
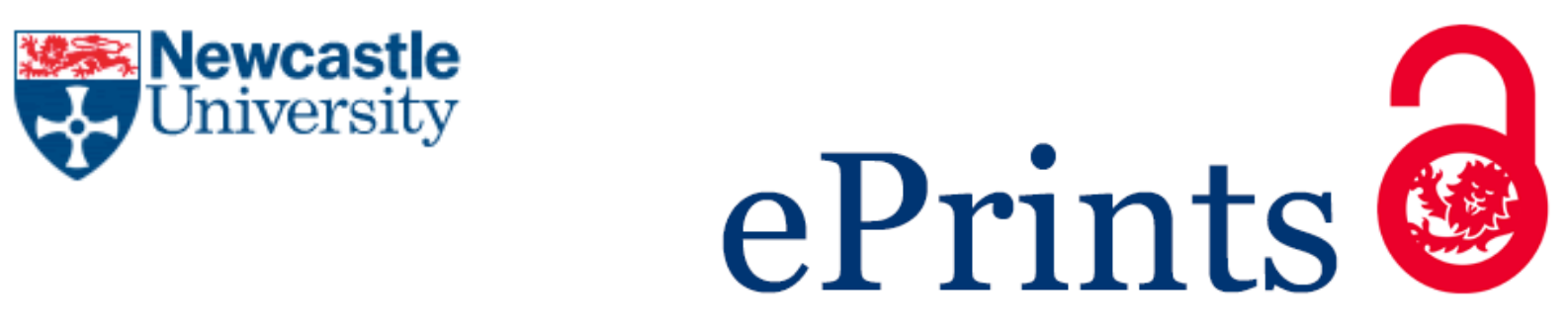

Seidl L, Bucher N, Chu E, Hartung S, Martens S, Schneider O, Stimming U.

Intercalation of solvated $\mathrm{Na}$-ions into graphite.

Energy and Environmental Science 2017, 10(7), 1631-1642.

\title{
Copyright:
}

C2017. This is the authors' accepted manuscript of an article that was published in its final definitive form by Royal Society of Chemistry, 2017.

DOI link to article:

https://doi.org/10.1039/C7EE00546F

Date deposited:

$17 / 11 / 2017$

Embargo release date:

31 May 2018

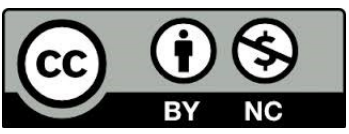

This work is licensed under a Creative Commons Attribution-NonCommercial 3.0 Unported License 


\section{Intercalation of Solvated Na-ions into Graphite}

Received 00th January 20xx Accepted 00th January 20xx DOI: $10.1039 / \times 0 \times x 00000 x$ www.rsc.org/

\author{
L. Seidl, ${ }^{a, b, c, d}$ N. Bucher, ${ }^{e}$ E. Chu, ${ }^{c}$ S. Hartung, ${ }^{e}$ S. Martens, ${ }^{b, c, d}$ O. Schneider ${ }^{b, c, d}$ and U. Stimming ${ }^{a, b}$, \\ $c, d, e, f$
}

The reversible intercalation of solvated $\mathrm{Na}$-ions into graphite and the concomitant formation of ternary Na-graphite intercalation compounds (GICS) is studied by several in-operando techniques, such as X-ray-diffraction (XRD), electrochemical scanning tunnelling microscopy (EC-STM) and the electrochemical quartz crystal microbalance technique (EQCM). Linear ethylene glycol dimethyl ether homologes ("glymes") $\mathrm{G}_{x}$ with $x+10$-atoms were used as solvents, where $x$ is 1-4. The intercalation mechanism of $\mathrm{Na}^{+}\left(G_{x}\right)_{y}$-complexes was investigated with the focus on phase transitions and diffusion rates of the $\mathrm{Na}^{+}\left(\mathrm{G}_{x}\right)_{y}$-complexes inside the graphite lattice. For the four shortest glymes $\left(\mathrm{G}_{1}\right.$ to $\left.\mathrm{G}_{4}\right)$, it is found by XRD that an intermediate stage $2 \mathrm{Na}-\mathrm{GIC}\left(\mathrm{NaC}_{48}\right)$ is formed upon partial sodiation of the graphite electrode. At full sodiation a stage 1 $\mathrm{Na}-\mathrm{GIC}\left(\mathrm{NaC}_{18}, 112 \mathrm{mAh} \mathrm{g}^{-1}\right)$ is obtained for $\mathrm{G}_{1}, \mathrm{G}_{2}$ and $\mathrm{G}_{4}$, while the $\mathrm{G}_{3}$-system is also forming a stage 1 Na-GIC but with less

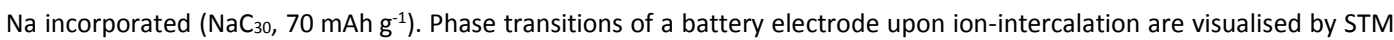
on the atomic scale for the first time. In addition, local diffusion rates of the intercalated species inside the electrode were determined, a unique approach to determining kinetic effects in batteries on the atomic scale. The formation of a solid electrolyte interphase (SEI) is observed in STM as well as in EQCM, while the latter technique is used as a novel in-situ hydrodynamic spectroscopy giving further insight into the intercalation mechanism.

\section{Introduction}

Recently, investigations of Na-ion batteries (NIBs) started and experienced a rapid development, which is reflected in the fast increasing number of publications. ${ }^{1}$ The driving force behind this are the potentially lower costs of NIBs compared to Li-ion batteries (LIBs), as the elemental abundance of $\mathrm{Na}$ in the earth's crust is about three orders of magnitude larger than the $\mathrm{Li}$ abundance. ${ }^{2}$ Hence, a big part of the battery costs can be reduced due to the lower raw material costs of $\mathrm{Na}^{3,}, 4,5,6$ Additionally, Al-current collectors can be used instead of $\mathrm{Cu}$ for the anode, since Na does not alloy with Al when operated as an anode as Li does, not only being advantageous in terms of costs, but also with respect to gravimetric energy and power density. ${ }^{2}$, 4, 5, 6,7 Moreover, the manufacturing costs of NIBs can be further reduced due to the fact that cheaper polymer binders (carboxymethyl cellulose $\mathrm{CMC}$ instead of polyvinylidene fluoride PVDF) can be used, together with less costly binder solvents (water instead of N-Methyl-2-pyrrolidon NMP). ${ }^{5}$

a.Physik-Department, Technische Universität München, James-Franck Straße 1, 85748 Garching, Germany. E-mail: Iukas.seidl@tum.de

b. Institut für Informatik VI, Technische Universität München, Schleißheimerstraße 90a, 85748 Garching, Germany.E-mail: oliver_m.schneider@tum.de

c. Electrochemical Research Group, Technische Universität München,

Schleißheimerstraße 90a, 85748 Garching, Germany

d. Joint Research Institute for Advanced Power Sources for Electric Vehicles,

Technische Universität München, 85748 Garching, Germany, Tsinghua University, 100084 Beijing, China

e. TUM CREATE, 1 CREATE Way, \#10-02 CREATE Tower, Singapore 138602, Singapore

f. School of Chemistry, Newcastle University, Newcastle Upon Tyne NE1 TRU, United Kingdom. E-mail: ulrich stimming@newcastle.ac.uk

† Footnotes relating to the title and/or authors should appear here.

Electronic Supplementary Information (ESI) available: [details of any supplementary information available should be included here]. See DOI: 10.1039/x0xx00000x
On the other hand, compared to LIBs, NIBs have certain shortcomings with respect to their atomic, ionic and electrochemical properties. $\mathrm{Na}(23.00 \mathrm{u})$ has an atomic weight higher than $\mathrm{Li}(6.94 \mathrm{u})$, a larger ionic radius (1.02 ̊ for $\mathrm{Na}^{+}$vs. $0.76 \AA$ for $\left.\mathrm{Li}^{+}\right)$and a more positive redox potential $\left(\mathrm{E}\left(\mathrm{Na} / \mathrm{Na}^{+}\right) \approx\right.$ $+0.3 \mathrm{~V}$ vs. $\left.\mathrm{Li} / \mathrm{Li}^{+}\right) .3,4,6,8$ While the increased atomic weight and redox potential directly result in a reduced energy density, the effect of the larger ionic radius is debated controversially. Often it is suggested in literature that the larger ionic radius hampers the ionic diffusion in the electrode. ${ }^{9,10}$ Other studies deny this relationship ${ }^{11}$ or even find an enhancement of $\mathrm{Na}$-ion diffusion, since the diffusion channels expand upon sodiation more than upon lithiation. ${ }^{12,13}$ This, however, can have a negative impact on the battery lifetime.10, 14, 15 Additionally, not all phase transitions and insertion reactions observed upon lithiation also occur upon sodiation, which reduces the number of possible electrode materials. ${ }^{16}$ On the other hand, the larger ionic size of $\mathrm{Na}$ can lead to the formation of new crystallographic phases, which are not observed for corresponding Li compounds. ${ }^{12}$

Suitable materials for the positive electrode operating at potentials up to $4 \mathrm{~V}$ with a capacity of up to $200 \mathrm{mAh} \mathrm{g}^{-1}$ are usually oxides, phosphates, fluorophosphates and fluorides. On the other hand, other metal oxides, sulfides, phosphorous materials and carbon materials are typically used as negative electrode with less than $2 \mathrm{~V}$ operating potential and capacities in the range of several hundred $\mathrm{mAh} \mathrm{g}^{-1}{ }^{-1,3,14,17}$ Especially the carbon based materials (hard carbons and graphite) moved into the focus of NIB-research, since the introduction of graphite anodes into NIBs is thought to be the next huge step towards their commercialization. ${ }^{18}$ Consequently, graphite is one of the most promising anode materials for NIBs. However, from classical carbonate based electrolytes it was not possible to reversibly intercalate $\mathrm{Na}$-ions in a sufficient amount. ${ }^{19,} 20,21$ 
Theoretical first principle calculations and density functional theory studies showed that $\mathrm{Na}$ can only intercalate to a minor extent to form binary graphite intercalation compounds (GICs) in carbonate based electrolytes, which are energetically unstable and where the in-plane Na diffusion in the graphite is hampered. ${ }^{11,22,23}$

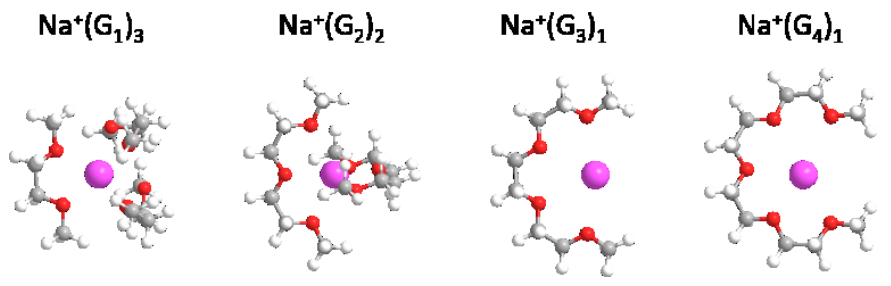

Figure 1: Ball-stick models of the $\mathrm{Na}^{+}\left(G_{x}\right)_{y}$ complexes for the different solvents resulting from an O-coordination number from 4 to $6 .{ }^{34}$ (pink: $\mathrm{Na}^{+}$, red: O-atom, grey: $\mathrm{C}$-atom, white: $\mathrm{H}$-atom)

Recently however, the formation of ternary GICs from ether based electrolytes was reported in literature, where di-glyme $\left(\mathrm{G}_{2}\right)$ was used as solvent in the electrolyte, coordinating the $\mathrm{Na}$ ions (Figure 1) and co-intercalating into the graphite according to: ${ }^{24}$

$$
\mathrm{C}_{\mathrm{n}}+\mathrm{e}^{-}+\mathrm{Na}^{+}+\mathrm{yG}_{2} \leftrightharpoons \mathrm{Na}^{+}\left(\mathrm{G}_{2}\right)_{\mathrm{y}} \mathrm{C}_{\mathrm{n}}^{-}
$$

Based on this work other linear glymes with longer chains were tested in NIBs and showed an excellent cycling behaviour with capacities close to $100 \mathrm{mAh} \mathrm{g}^{-1}$ and several thousand cycles without significant capacity losses. ${ }^{25,} 26,27$ This led to the operation of the first full cell, combining a graphite anode with a $\mathrm{P} 2-\mathrm{Na}_{0.7} \mathrm{CoO}_{2}$ cathode and a tetra-glyme $\left(\mathrm{G}_{4}\right)$ based electrolyte. ${ }^{28}$ Other studies on the formation of ternary Na-GICs followed. ${ }^{29}, 30,31,32,33$ Jache's recent study ${ }^{34}$ focused on the electrochemical difference for the first four glymes, which showed a similar behaviour for mono-glyme $\left(G_{1}\right)$, di-glyme and tetra-glyme. Tri-glyme $\left(\mathrm{G}_{3}\right)$, however, showed different phase transitions in electrochemical tests. The origin of this difference is still an open question. Other unclear points concern the mechanistic understanding of the phase transitions caused by the intercalation of the solvated $\mathrm{Na}$-ions, the solvation structure of the latter, their diffusion behaviour inside the graphite lattice as well as the formation of a solid-electrolyte-interface (SEI) on the graphite electrode in the glyme electrolytes.

Due to the expected large potential importance of graphite as anode material in NIBs, a much more detailed understanding of the intercalation processes in graphite and also the SEI formation in the glyme based electrolytes is required. Therefore, this paper gives further insight into the underlying electrochemistry and the influence of the solvent molecule making use of a combination of several novel experimental approaches. These are in-operando techniques, such as nonsynchrotron X-ray diffraction (XRD), giving insight into the graphite lattice expansion, phase transitions and staging processes, the electrochemical scanning tunnelling microscopy (EC-STM), visualizing these phase transitions in real time and providing a direct measure of local diffusion rates of the $\mathrm{Na}^{+}\left(\mathrm{G}_{\mathrm{x}}\right)_{\mathrm{y}}$-complexes inside the graphite, and the electrochemical quartz crystal microbalance technique (EQCM), which is operated as the novel in-situ hydrodynamic spectroscopy technique to study intercalation processes in battery electrodes. The combination of these techniques complement electrochemical measurements, like cyclic voltammetry (CV) and galvanostatic charge/discharge

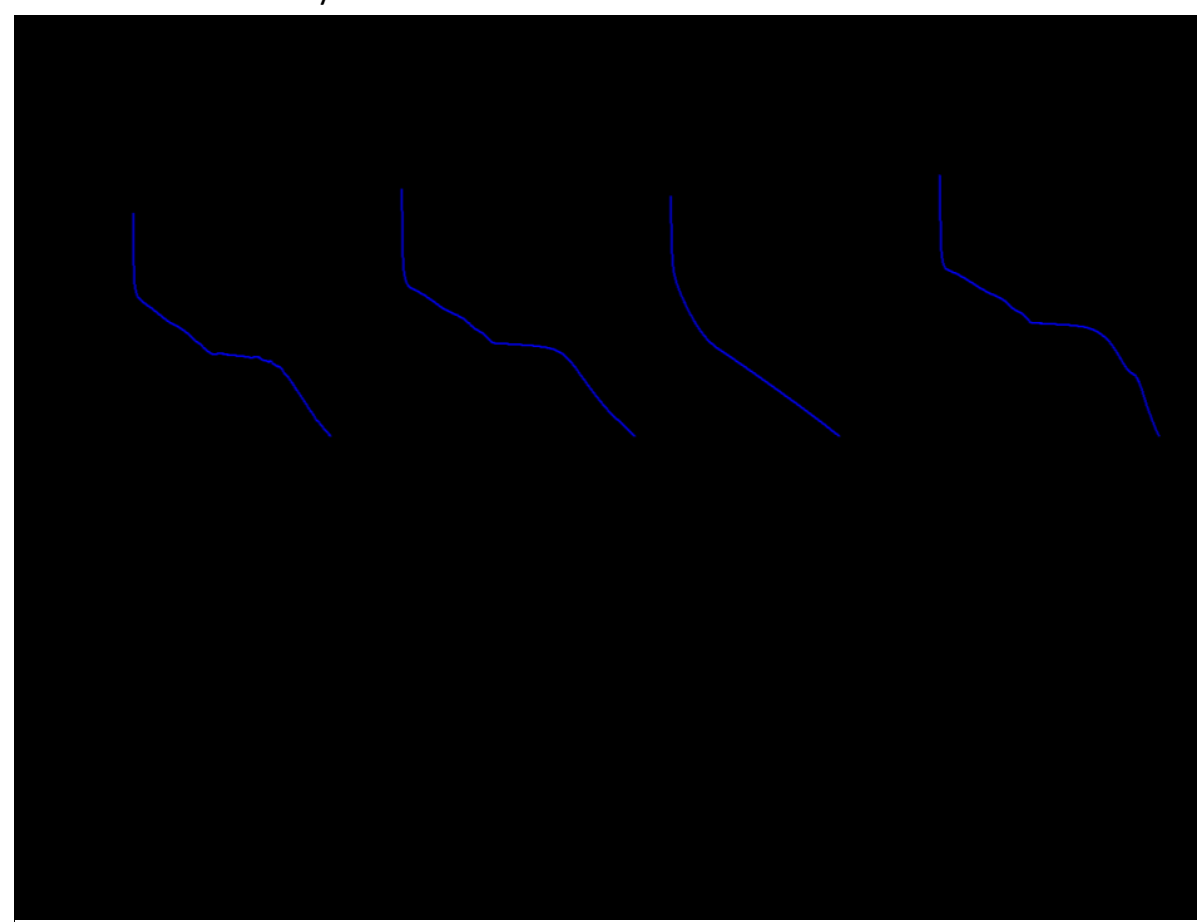

Figure 2: Exemplary charge (black)/discharge (blue) profiles of the $2^{\text {nd }}$ cycle and the corresponding dQ/dV-plot of MCMB in $1 \mathrm{M} \mathrm{NaClO}_{4}$ in $(a, b) G_{1},(c, d) G_{2},(e, f) G_{3}$ and $(g, h) G_{4}$ measured at a current density of $50 \mathrm{~mA} \mathrm{~g}^{-1}$. Formulas indicate stoichiometry at potentials above the main potential plateau and in fully intercalated state. 
experiments, and tackle open questions by shedding more light on the underlying chemistry and intercalation mechanisms.

\section{Results}

\section{Electrochemistry}

Figure 2 shows the charge/discharge data of a graphitic mesoporous carbon micro bead (MCMB) electrode cycled as working electrode (WE) in a three electrode Swagelok ${ }^{\circledR}$ cell with a Na reference and counter electrode (RE and CE, respectively), which was cycled at a current density of $50 \mathrm{~mA} \mathrm{~g}^{-1}$ in an electrolyte composed of $1 \mathrm{M} \mathrm{NaClO}_{4}$ in the different glymes, i.e. $\mathrm{G}_{1}, \mathrm{G}_{2}, \mathrm{G}_{3}$ and $\mathrm{G}_{4}$. As in this study a $\mathrm{Na}$ counter electrode was used (cf. supplemental information), the term "discharge" in the following relates to sodium intercalation into graphite, while "charge" corresponds to de-intercalation. Since the excellent cycling stability of graphite electrodes in glyme based electrolytes was already demonstrated in previous studies, ${ }^{24,25}$, $26,28,34,35$ only the voltage profiles of the $2^{\text {nd }}$ charge/discharge

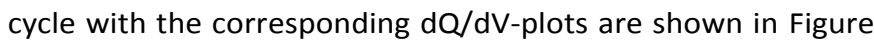
2, where (a) and (b) refer to $G_{1},(c)$ and (d) to $G_{2}$, (e) and (f) to $\mathrm{G}_{3}$ and $(\mathrm{g})$ and $(\mathrm{h})$ to $\mathrm{G}_{4}$. The full charge/discharge data sets can be found in the supporting information in Figure SI 1.

The observed capacities are in the range of 70 to $100 \mathrm{mAh} \mathrm{g}^{-1}$, which, however, should be taken with caution, since the measured capacities can severely scatter from experiment to experiment. This can be seen from the black dots, which are sketched into the diagram (e) to ( $h$ ) in Figure SI 1 after 10 cycles. Each dot corresponds to a different battery and clearly shows over which range the capacity scatters. Also when comparing the different capacities found in literature, one can find numbers ranging from 50 up to $150 \mathrm{mAh} \mathrm{g}^{-1} .24,25,26,28,34,35$ Due to this uncertainty, the capacity and its relation to the glyme solvent shall not be overrated here. The reproducibility in the $\mathrm{G}_{3}$ - and $\mathrm{G}_{4}$-electrolyte is much better than in the $\mathrm{G}_{1^{-}}$and $\mathrm{G}_{2-}$ electrolyte. The reason for this difference is currently unclear, but worth to be studied in further detail, since one might obtain also valuable information about electrode failure and battery lifetime.

More interesting than the voltage profiles are the $\mathrm{dQ} / \mathrm{dV}$-plots (Figure 2), which show the same behaviour as the CVs in Figure SI 2/3. They show a fundamental difference in the electrochemical behaviour of the $\mathrm{G}_{3}$ system compared to the other electrolytes. While one can see a multitude of cathodic peaks in case of $G_{1}, G_{2}$ and $G_{4}$, namely four small peaks followed by a sharp spike and a low voltage peak in case of $G_{2}$ and $G_{4}$, only one broad cathodic peak is visible in the $G_{3}$ electrolyte. On the other hand, the anodic peaks in the $G_{1}, G_{2}$ and $G_{4}$ are smeared out, while a multitude of sharp anodic peaks is observed in case of $G_{3}$. This fundamental difference in electrochemical behaviour is one of the issues, which shall be addressed in this study applying a variety of powerful characterization techniques.

From the capacities of the plateaus in the voltage profiles one can calculate the stoichiometry of the ternary Na-GICs (further details on the calculation can be found in the $\mathrm{SI}$ ), which is shown for each electrolyte in the respective $d Q / d V$-plot. Here, the stoichiometry of the Na-GIC was calculated for the GIC at potentials larger than the main potential plateau and of the fully discharged (fully intercalated) electrode. This was done for the discharge curves in case of $G_{1}, G_{2}$ and $G_{4}$, while for $G_{3}$, the charge curve was taken as the discharge curve showed no plateau. As will be shown in the next section, where XRD was used to study these systems, a major phase transition is correlated with this plateau, respectively peak. From the inserted electrical charge one finds a stoichiometry at the beginning (end in case of $\mathrm{G}_{3}$ ) of this plateau close to $\mathrm{NaC}_{50}$ in all systems. Fully discharged, the three systems $G_{1}, G_{2}$ and $G_{4}$ reach a stoichiometry of close to $\mathrm{NaC}_{20}$, while a $\mathrm{NaC}_{30}$-composition is found for the $\mathrm{G}_{3}$ system.

\section{In-operando XRD}

Figure 3 shows a series of in-operando XRD diffractograms, where graphite in the form of $\mathrm{MCMB}$ was galvanostatically charged/discharged in $1 \mathrm{M} \mathrm{NaClO}_{4}$ in the four different glymes $G_{1}, G_{2}, G_{3}$ and $G_{4}$, while XRD data of the electrode were recorded with a time resolution of ten minutes. The full diffractograms can be seen in Figure $\mathrm{SI} 4$ in the supporting information, where also XRD data of a graphite electrode in classical carbonate electrolytes are presented (Figure SI 5).

Figure 3 (a) shows the diffractograms of graphite in the $G_{1}$ electrolyte, while the first (i.e. $t_{0}=0 \mathrm{~s}$ ) diffractogram correlates with the pristine electrode. Here, the main (002)-graphite peak originating from the $3.35 \AA$ interlayer spacing of the graphene layers is visible at $26.42^{\circ}$. Discharging the graphite leads to a splitting of this peak into two new peaks, one at larger and one at smaller angle, while the original peak disappears. Both peaks then continuously shift to higher and lower angles, until the angle remains constant at $23.5^{\circ}$ and $29.6^{\circ}$. This can also be seen in the supporting information Figure SI 6 (a), where the peak positions are compared to the charge-/discharge-profile and the applied electrode potential. As soon as the discharge plateau at $0.5 \mathrm{~V}$ is reached, which causes the sharp cathodic peak in the dQ/dV-plot (Figure $2(b)$ ), the formation of a new phase is observed in the XRD-data resulting in peaks at $22.87^{\circ}$ and $30.6^{\circ}$, respectively, where the second peak is a higher order peak of the first one. In the diffractograms themselves (Figure 3 (a)), one can make out even lower/higher order peaks of this phase at ca. $15.2^{\circ}$ and $38.1^{\circ}$. After the discharge is stopped at $0.01 \mathrm{~V}$ the electrode is charged again, which leads to the gradual disappearance of the latter phase. As soon as the kink in the charge curve at $0.67 \mathrm{~V}$ is reached, which causes the large anodic peak in the $\mathrm{dQ} / \mathrm{dV}$-plot (Figure 2 (a)), the intermediate phase $\left(23.5^{\circ}\right.$ and $\left.29.6^{\circ}\right)$ is formed again, while the peaks now continuously approach until they merge to the main (002)-graphite peak at $26.42^{\circ}$ upon full charge at $2.0 \mathrm{~V}$.

$$
n \cdot \lambda=2 d \sin \theta=2 \cdot \frac{c}{l} \cdot \sin \theta
$$

Applying Bragg's law (cf. Equation (2)), one can determine the Miller indices $/$ and $I+1$ for the XRD peaks of the thus formed GIC according to equation (3): 26,36 


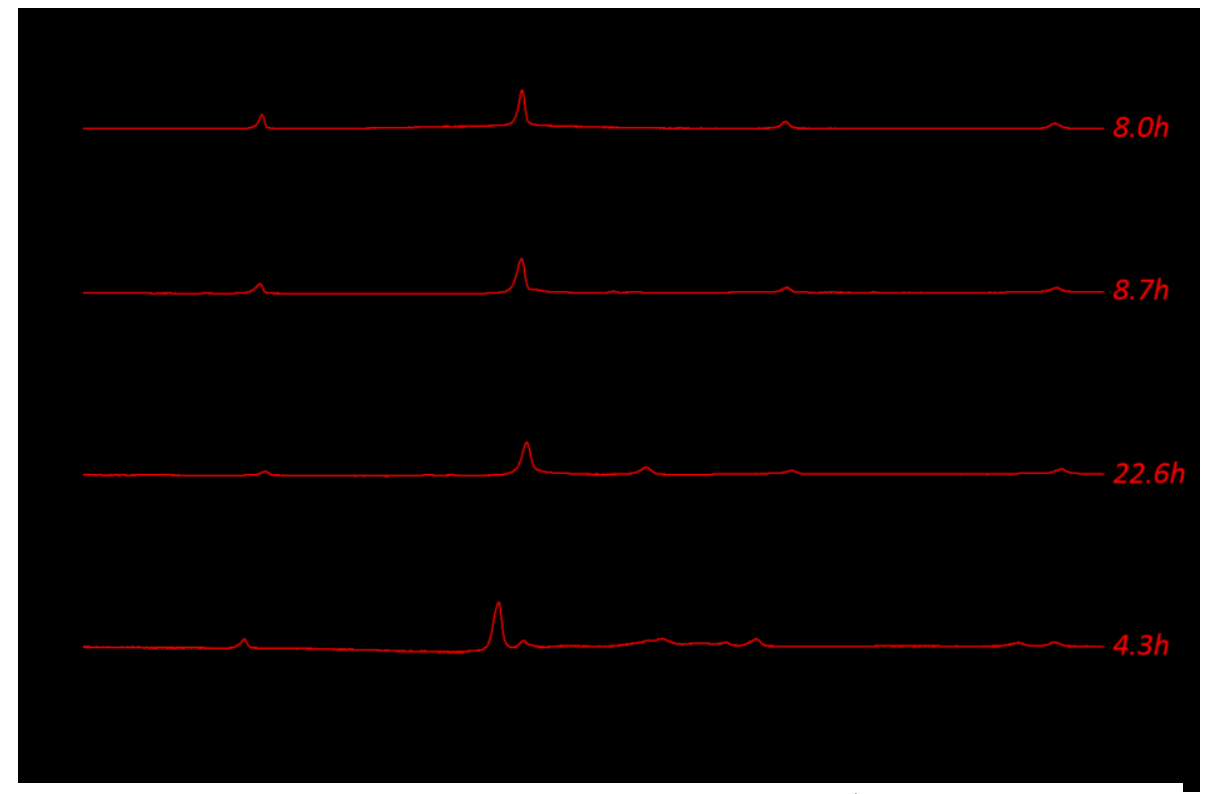

Figure 3: In-operando X-Ray diffractograms of the reversible $\mathrm{Na}$-ion intercalation/de-intercalation into a graphite electrode in $1 \mathrm{M} \mathrm{NaClO}_{4}$ in (a) $\mathrm{G}_{1}$, (b) $\mathrm{G}_{2}$, (c) $\mathrm{G}_{3}$ and (d) $\mathrm{G}_{4}$ with the red line at $0.01 \mathrm{~V}$ marking the crossover between discharge and charge. The total time after which each respective XRD was recorded is indicated in the graph, the numbers refer to the total time of discharge (in red) and discharge + charge (in black).

$$
l=\frac{1}{\left[\frac{\sin \theta_{00(l+1)}}{\sin \theta_{00 l}}-1\right]}
$$

where $\theta_{0 o l}$ and $\theta_{0 o(l+1)}$ are the Bragg angles of the $(00 /)$ and $(00 /+1)$ peak, respectively.

Figure SI 7 (a) in the supporting information shows the development of the $I$-value in the course of charge/discharge, which steadily drops upon sodiation until it reaches a fixed value of 4 , being caused by the intermediate phase transition resulting in the XRD-peaks at $23.5^{\circ}(004)$ and $29.6^{\circ}(005)$. With the onset of the phase transition observed at $0.5 \mathrm{~V}$ an $I$-value of 3 is calculated for the new phase from the XRD peaks at $22.87^{\circ}$ and $30.6^{\circ}$. Upon charging, the latter phase transforms again into the intermediate phase $(I=4)$ and shortly into a phase showing peaks for $I=5$ again, before the graphite reaches its original state when fully charged at $2.0 \mathrm{~V}$.

With this information one can convert the $d$-spacing calculated for each XRD peak from the Bragg equation to the lattice constants $c$ of the different GICs, which amount in $\mathrm{G}_{1}$ to e.g. $15.12 \AA$ for $2 \theta=23.5^{\circ}$ for the intermediate phase and $11.65 \AA$ for $2 \theta=22.87^{\circ}$ after full sodiation. This is in full agreement with results of Kim et al. ${ }^{26}$.

Similar observations are made for the other electrolytes, i.e. $\mathrm{G}_{2}$, $\mathrm{G}_{3}$ and $\mathrm{G}_{4}$ in Figure 3 (b), (c) and (d), respectively. While the $\mathrm{G}_{2}$ system only shows small differences in comparison to the $\mathrm{G}_{1}$ electrolyte, which mainly are slightly different peak positions, the diffractograms of $\mathrm{G}_{3}$ and $\mathrm{G}_{4}$ look apparently different. The main difference is the absence of the main (002)-graphite peak in the beginning of the XRD series. This is due to the fact that one can see the diffractograms of the first charge/discharge cycle in $G_{1}$ and $G_{2}$, while later cycles are shown for $G_{3}$ and $G_{4}$. This peak is always very pronounced before the first cycle, however, its intensity never reaches its original value after cycling. In case of $\mathrm{G}_{3}$ one can see another difference to the other measurements, which is the appearance of the (002)-graphite peak throughout the entire cycle, which can be explained by graphite pieces loosely connected to the electrode, which were electrochemically inactive. Moreover, the peak intensities in the $G_{3}$ diffractograms behave different than in the other electrolytes. The peak positions with respect to the applied electrode potential can be found in the supporting information (Figure SI 6).

An interesting observation arises from the analysis of the Miller indices $/$ in the respective electrolytes (summarized in 


\section{Journal Name}

Table 1 and shown in Figure SI 7), from which the staging number of the corresponding $\mathrm{Na}-\mathrm{GIC}$ can be determined. Similar as in the study of Kim et al. ${ }^{26}$, a transition of the Miller indices from 5 to 4 to 3 upon sodiation is observed in this study in the $\mathrm{G}_{1^{-}}, \mathrm{G}_{2^{-}}$and $\mathrm{G}_{4}$-electrolyte, which therefore corresponds to a stage 3 , stage 2 and stage $1 \mathrm{Na}-\mathrm{GIC}$, respectively. In order to determine the staging number for the $\mathrm{G}_{3}$-system, where a transition from 4 to 3 is observed, an HOPG chip was fully sodiated (c.f. Figure SI 9) and the resulting volume expansion suggests also a stage $1 \mathrm{Na}-\mathrm{GIC}$. Moreover, this experiment shows that each $\mathrm{Na}$-ion is coordinated by a single $\mathrm{G}_{3}$-molecule upon intercalation. Thus, exactly as in the $\mathrm{G}_{1^{-}}, \mathrm{G}_{2^{-}}$and $\mathrm{G}_{4^{-}}$ systems, the $\mathrm{G}_{3}$-electrolyte forms a stage $2 \mathrm{GIC}$ in the intermediate phase transition, which upon further discharge goes over into a stage $1 \mathrm{GIC}$. 
Table 1 summarizes the findings about the lattice constants $c$ of the different phases determined from XRD measurements as well as the interlayer spacing between two graphene layers separated by intercalated $\mathrm{Na}$ ions. 
Table 1: Interlayer spacings, lattice constants, Miller indices and staging numbers of the sodiated graphite lattice found by XRD.

\begin{tabular}{ccccc}
\hline Electrolyte & $\begin{array}{c}\text { Interlayer spacing / lattice } \\
\text { constant c (intermediate } \\
\text { stage 2 Na-GIC) / }\end{array}$ & $\begin{array}{c}\text { Interlayer spacing (fully } \\
\text { discharged stage 1 Na- } \\
\text { GIC) / }\end{array}$ & Miller indices I & Staging $\mathrm{n}$ \\
\hline $1 \mathrm{M} \mathrm{NaClO}_{4} \mathrm{G}_{1}$ & $11.77 / 15.12$ & 11.65 & $5 \rightarrow 4 \rightarrow 3$ & $3 \rightarrow 2 \rightarrow 1$ \\
$1 \mathrm{M} \mathrm{NaClO}_{4} \mathrm{G}_{2}$ & $11.70 / 15.05$ & 11.85 & $5 \rightarrow 4 \rightarrow 3$ & $3 \rightarrow 2 \rightarrow 1$ \\
$1 \mathrm{M} \mathrm{NaClO}_{4} \mathrm{G}_{3}$ & $11.60 / 14.95$ & 11.59 & $4 \rightarrow 3$ & $2 \rightarrow 1$ \\
$1 \mathrm{M} \mathrm{NaClO}_{4} \mathrm{G}_{4}$ & $12.12 / 15.47$ & 12.01 & $5 \rightarrow 4 \rightarrow 3$ & $3 \rightarrow 2 \rightarrow 1$ \\
\hline
\end{tabular}

\section{In-operando EC-STM}

In contrast to XRD, which is an integral technique, EC-STM images local structures possibly providing further insight into the Na-intercalation into graphite. In order to image electrochemical processes by STM, single crystalline graphite model electrodes, such as highly oriented pyrolytic graphite (HOPG), are required, which show a very similar electrochemistry as graphite powder electrodes (Figure SI 3). The STM-studies presented here are restricted to the $\mathrm{G}_{3}$ and $\mathrm{G}_{4}$
The second image (Figure 4 (b)), which was scanned from top to bottom and from $0.75 \mathrm{~V}$ to $0.5 \mathrm{~V}$, shows some almost horizontal lines in the very upper part. These lines originate from a lattice expansion of the graphite (002)-plane, which is visible in real time here. In comparison to the image of the pristine sample, one can clearly see, how and where the graphite lattice expansion takes place. Thus, as soon as the electrode potential is negative enough, the graphite lattice expands due to an increase of the interplanar spacing of the graphene layers upon

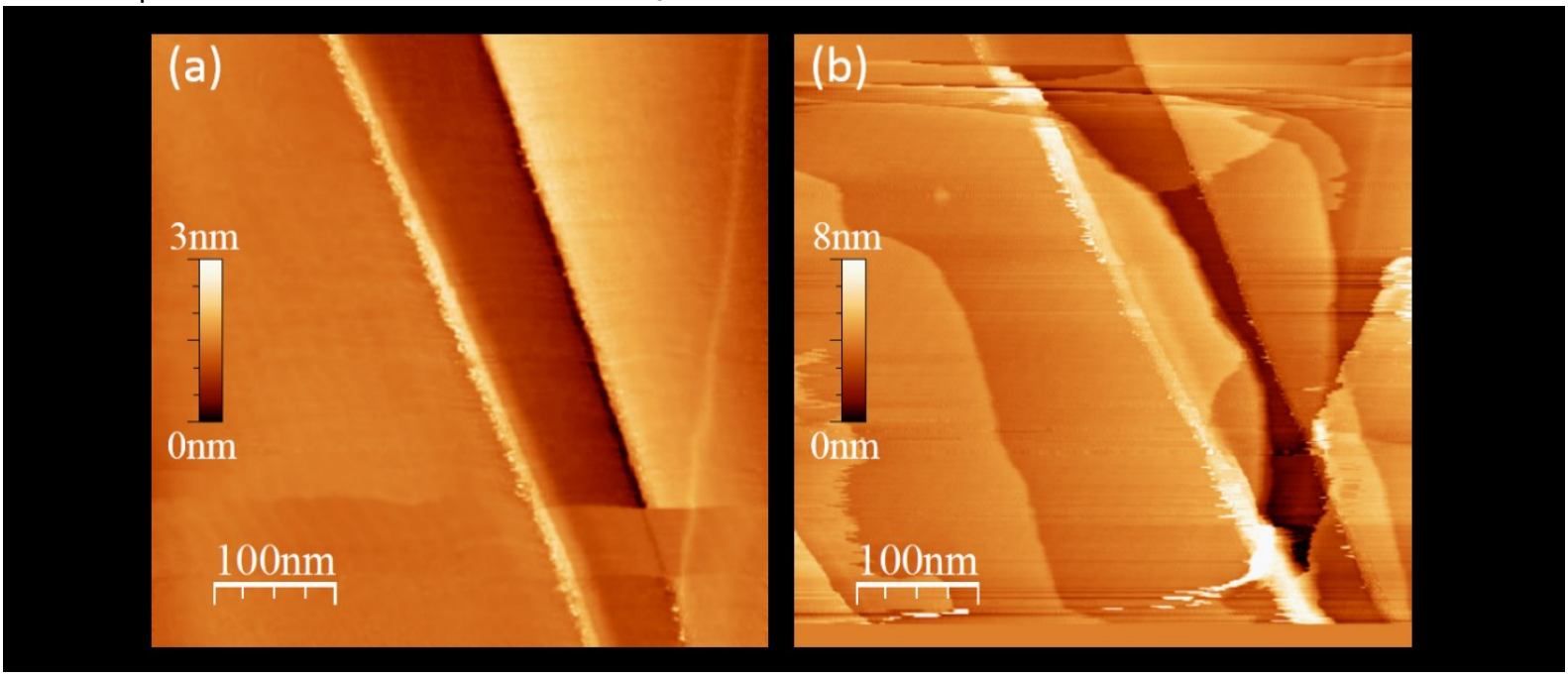

Figure 4: EC-STM of HOPG in $1 \mathrm{M} \mathrm{NaClO}_{4}$ in $\mathrm{G}_{3}$ of $(\mathrm{a})$ the pristine $(1.1 \mathrm{~V}$ to $0.75 \mathrm{~V})$ and (b) the partially discharged sample $(0.75 \mathrm{~V}$ to $0.5 \mathrm{~V})$. (tunnelling current: $8 \mathrm{nA}$, scan rate: $1 \mathrm{~Hz}$, tip potential: $2.6 \mathrm{~V}$, potential sweep rate: $5 \mathrm{mV} \mathrm{s}^{-1}$ )

electrolytes, since the $\mathrm{G}_{1}$ and $\mathrm{G}_{2}$ solvents are too volatile and evaporate within minutes, while recording a series of STM images lasts approximately two hours. The $\mathrm{G}_{3}$ and $\mathrm{G}_{4}$ electrolytes, however, do not evaporate over a period of several days.

Figure 4 shows STM images of a HOPG electrode immersed in $1 \mathrm{M} \mathrm{NaClO}_{4}$ in $\mathrm{G}_{3}$ recorded in-operando, while the potential was varied from $1.1 \mathrm{~V}$ to $0.75 \mathrm{~V}$ (Figure $4(\mathrm{a})$ ) and from $0.75 \mathrm{~V}$ to $0.5 \mathrm{~V}$ (Figure 4 (b)). Both images are part of a series of STM images recorded at the same position in parallel to a simultaneous CV measurement (Figure SI 10). Figure 4 (a) shows the pristine HOPG sample with all the typical HOPG features as the largely extended, atomically flat terraces, being interrupted by atomic step edges crossing the image; two step edges are visible, with the right one being five atom layers high.
Na-intercalation. While XRD is an integral technique, STM allows to quantify local topographical changes, such as the lattice expansion of a single graphene layer by measuring height profiles. Doing so, one can find graphite interlayer spacings, of $10.9 \AA$, compared to a d-spacing of $3.35 \AA$ of the pristine graphite. The interlayer spacing determination from STM images is explained in the supporting information (Figure SI 11). A different STM experiment is shown in Figure 5, where the electrode potential was scanned from $2.5 \mathrm{~V}$ to $0.5 \mathrm{~V}$ (a) and then back to $2.5 \mathrm{~V}$ (b). In these experiments the STM images have been rotated by $90^{\circ}$ as compared to those in Figure 4, to convert the original $y$-axis into a time axis. One interesting observation is the appearance of the five almost vertical lines at potentials below $0.8 \mathrm{~V}$ in Figure $5(\mathrm{a})$, which occur in the same potential regime as the lines appearing in Figure 4 (b). These lines can also 


\section{ARTICLE}

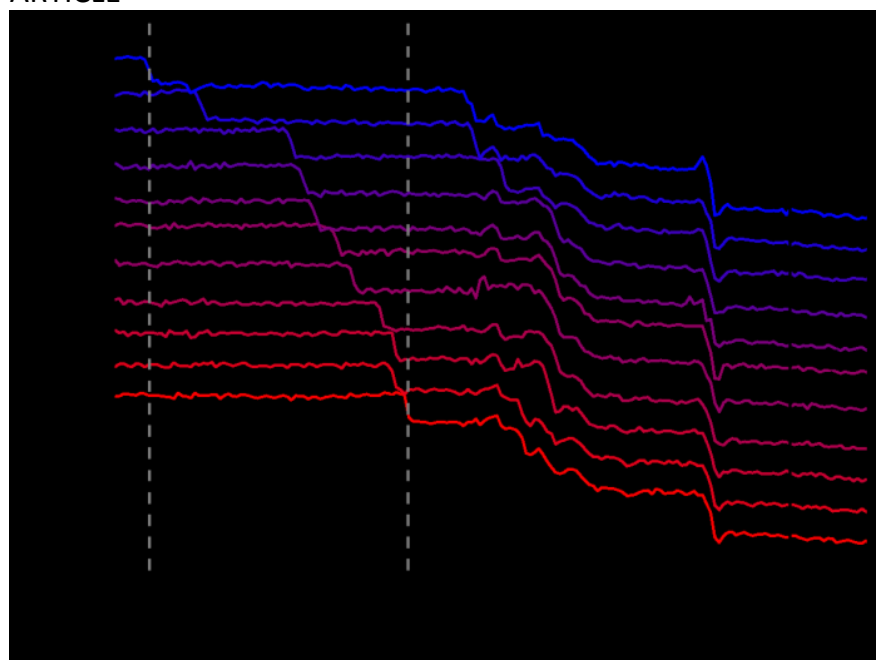

Figure 6: Temporal propagation of the graphite lattice expansion. For clarity the line scans are shifted by $1.5 \mathrm{~nm}$ in y-direction.

be found in the anodic potential scan in Figure 5 (b) at potentials between $1.0 \mathrm{~V}$ and $1.5 \mathrm{~V}$. They perfectly match the current peaks observed in the corresponding $l(t)$ curve (cyan line), which was measured in parallel to STM. As before (Figure 4), one can find a lattice expansion of the graphite upon the phase transitions caused by a lattice expansion (anodic scan) and contraction (cathodic scan). Figure 6 shows a time series of height profiles measured along the blue line indicated in Figure 5 (b) as a function of time. These height profiles were shifted from left to right pixel by pixel, while the time difference between each line is $1 \mathrm{~s}$. Moving the height profile over the area, where the phase transitions are observed, one can follow the propagation of the extended graphite lattice and measure, how the expansion moves across the electrode. In the example shown in Figure 6 the graphite expansion retracted $59 \mathrm{~nm}$ in $10 \mathrm{~s}$, resulting in a diffusion rate of $5.9 \mathrm{~nm} \mathrm{~s}^{-1}$.

Varying the electrolyte solvent, $\mathrm{G}_{4}$ was used instead of $\mathrm{G}_{3}$. Figure 7 (a) shows a series of in-operando EC-STM images measured in $1 \mathrm{M} \mathrm{NaClO}_{4}$ in $\mathrm{G}_{4}$. The left image shows the pristine HOPG surface at a potential of $2.5 \mathrm{~V}$, where it remains unaffected for several hours. Then, is was ramped to $0.8 \mathrm{~V}$ at $5 \mathrm{mV} \mathrm{s}^{-1}$ and held there for $428 \mathrm{~s}$, before the middle image was measured (256 s) and finally ramped back to $2.5 \mathrm{~V}$ and held there for another $428 \mathrm{~s}$ before starting the STM scan (right). At $0.8 \mathrm{~V}$ multiple phase transitions caused by a lattice expansion can be observed. These phase transitions are different in character compared to $G_{3}$, where the phase transitions are clearly separated. In $\mathrm{G}_{4}$ they partially overlap, partially occur in parallel but no clear pattern is visible. This can be even clearer seen in another STM-series shown in the SI, where STM is performed in parallel to a CV-scan (Figure SI 12). Raising the potential back to $2.5 \mathrm{~V}$, lattice contractions associated with

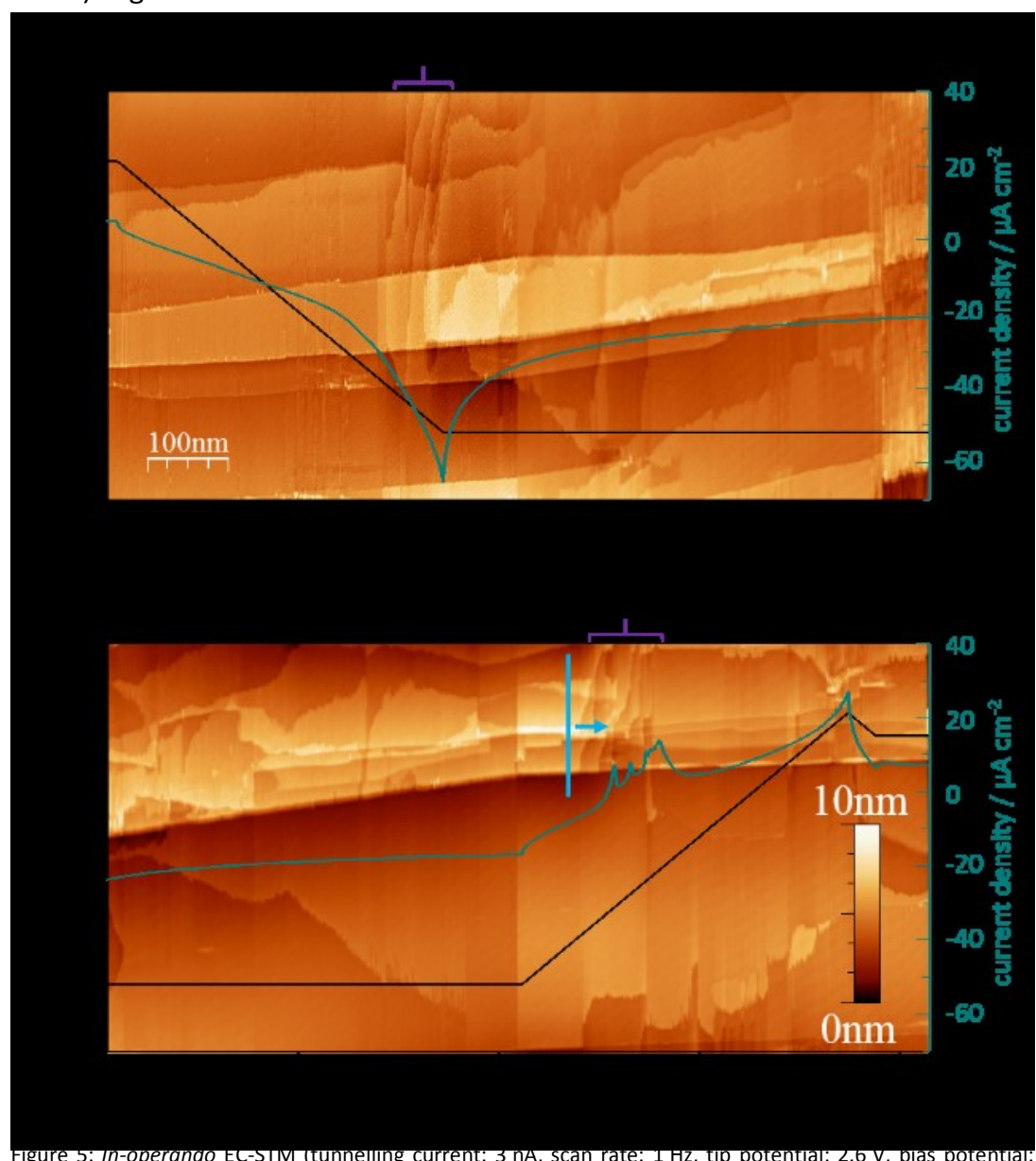

variable) of $\mathrm{HOPG}$ in $1 \mathrm{M} \mathrm{NaClO}_{4}$ in $\mathrm{G}_{3}$ during (a) the $\mathrm{Na}$-ion intercalation and (b) the $\mathrm{Na}$-ion de-intercalation, while a $\mathrm{CV}$ was measured (sweep rate: $5 \mathrm{mV} \mathrm{s}^{-1}$ ) shown as $U(t), I(t)$ curves. 
phase transitions can be observed. At the positions indicated by coloured horizontal lines in the images of Figure 7 (b), height profiles were measured. They indicate, how the graphite lattice expands at $0.8 \mathrm{~V}$ (red) as compared to the pristine sample (black), and how the lattice shrinks to its original state when going back to $2.5 \mathrm{~V}$ (blue). Also for the $\mathrm{G}_{4}$ system diffusion rates of the extended graphite lattice can be evaluated, which on average yield $22.1 \mathrm{~nm} \mathrm{~s}^{-1}$. All data, including lattice expansions and diffusion rates from the STM-analyses are summarized in Table 2.

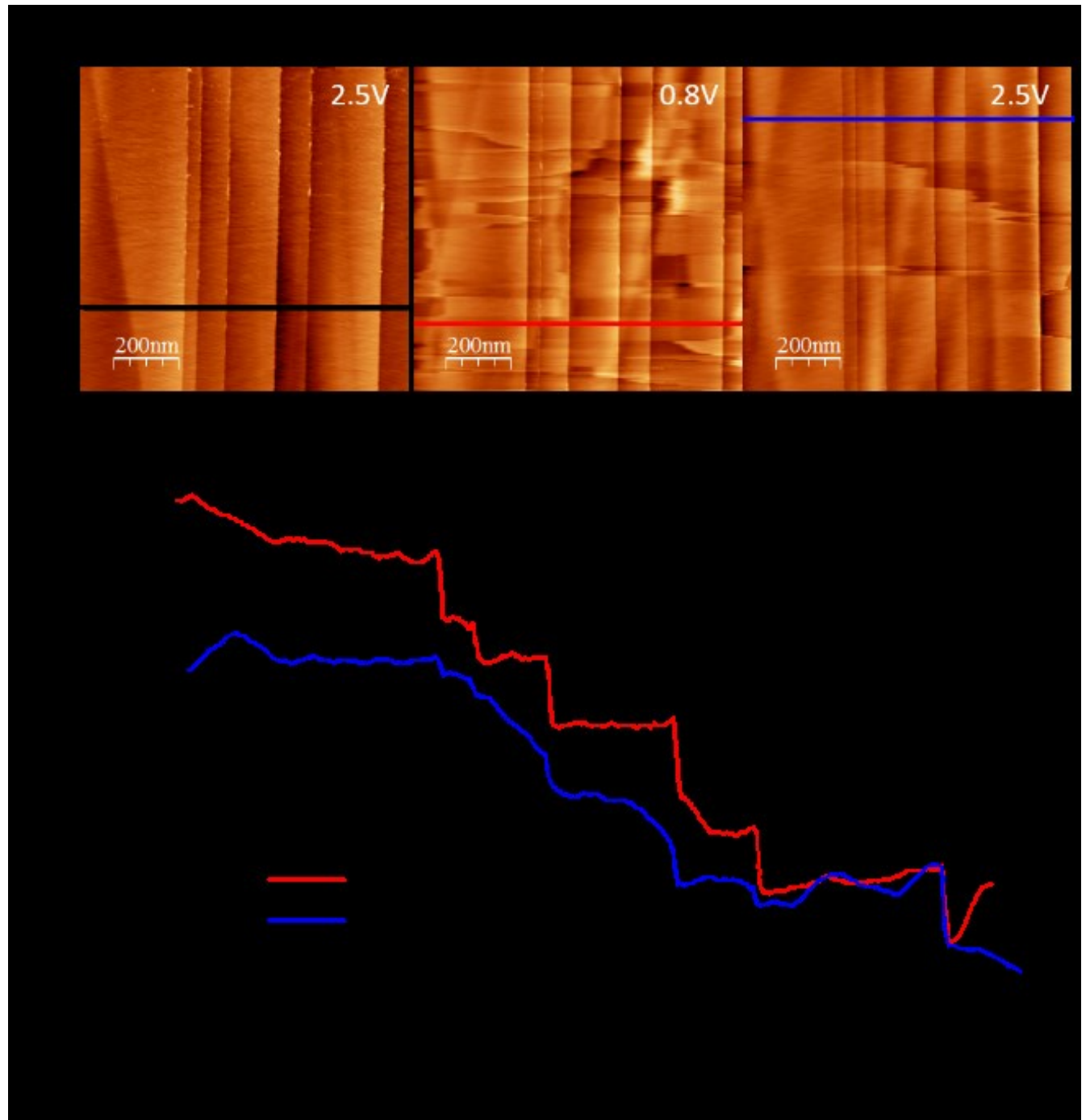

Figure 7: (a) In-operando EC-STM (tunnelling current: $1 \mathrm{nA}$, scan rate: $1 \mathrm{~Hz}$, tip potential: $2.6 \mathrm{~V}$, bias potential: variable) of HOPG in $1 \mathrm{M}$ $\mathrm{NaClO}_{4}$ in $\mathrm{G}_{4}$ showing the pristine sample with a potential held at $2.5 \mathrm{~V}$ (left), the partially discharged sample at $0.8 \mathrm{~V}$ (middle) and the charged sample at $2.5 \mathrm{~V}$ with (b) the corresponding height profiles measured along the lines indicated in (a).

Table 2: Comparison of the Na-ion diffusion rates upon intercalation/de-intercalation and the interlayer distance between two adjacent graphene layers in the sodiated graphite from the STM data obtained in $1 \mathrm{M} \mathrm{NaClO}_{4} \mathrm{G}_{3}$ and $1 \mathrm{M} \mathrm{NaClO}_{4} \mathrm{G}_{4}$. The values are calculated from statistical data, while the error is the standard deviation.

\begin{tabular}{ccc}
\hline Electrolyte & Na-ion diffusion rate $/ \mathrm{nm} \mathrm{s}^{-1}$ & Interlayer spacing / \\
\hline $1 \mathrm{M} \mathrm{NaClO}_{4} \mathrm{G}_{3}$ & $5.9 \pm 1.2$ & $10.9 \pm 0.2$ \\
$1 \mathrm{M} \mathrm{NaClO}_{4} \mathrm{G}_{4}$ & $22.1 \pm 5.5$ & $10.7 \pm 0.2$ \\
\hline
\end{tabular}

\section{In-operando EQCM}

A, so far, rarely used experimental approach to study intercalation phenomena in carbon materials is the electrochemical quartz crystal microbalance technique, which can give further insight into the ongoing processes. Figure 8 shows an experiment, where a standard Au-coated $10 \mathrm{MHz}$ AT-cut quartz was decorated with graphite particles in order to mimic real battery electrodes. While measuring a $\mathrm{CV}$ of the graphite particles in the $\mathrm{G}_{3}$ electrolyte, the resonance frequency $f$ and the damping of the quartz oscillation $w$ were recorded. The CV (black) in Figure 8 (a) shows a broad cathodic peak extending over a wide potential range. The anodic scan shows the typical peaks between $1.0 \mathrm{~V}$ and $1.5 \mathrm{~V}$, as they are already observed in Figure 2 and Figure 5. The slight grey CV shown in this figure is a CV measured with a powder graphite electrode in a Swagelok ${ }^{\circledR}$ cell 

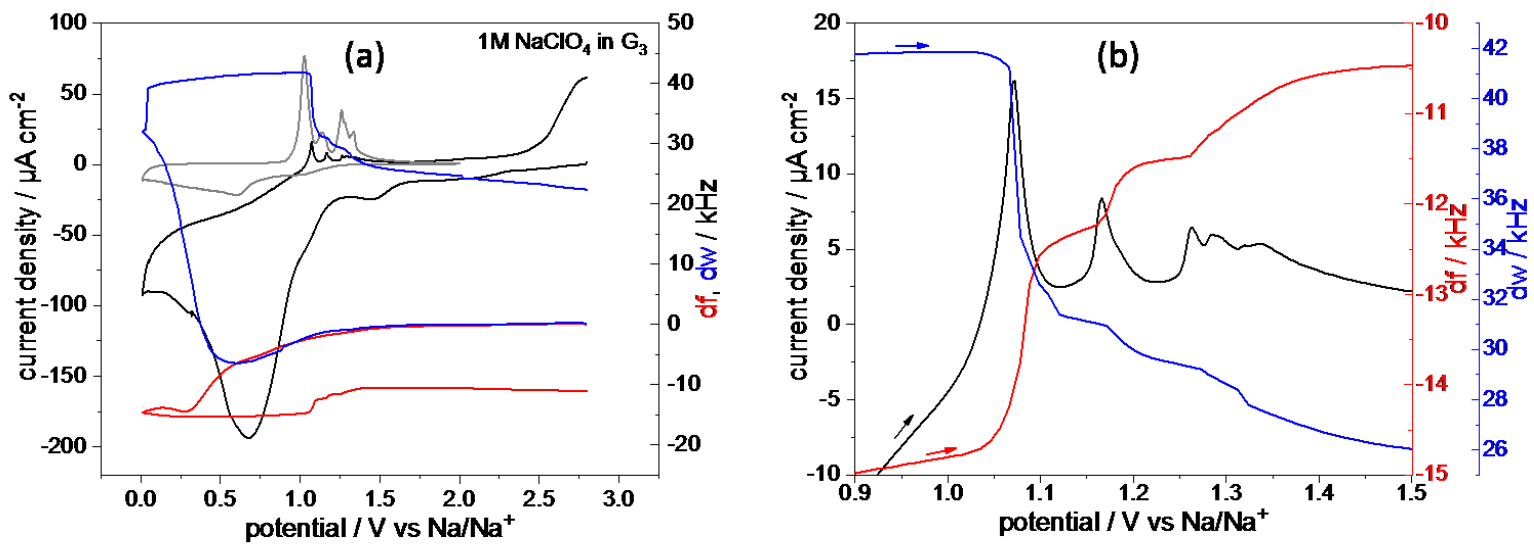

Figure 8: In-operando EQCM of SFG6 graphite coated on an Au-quartz in $1 \mathrm{M} \mathrm{NaClO}_{4}$ in (a) $\mathrm{G}_{3}$ with (b) a magnification of the de-sodiation peaks (sweep rate: $2 \mathrm{mV} \mathrm{s}^{-1}$ ). The light grey CV (sweep rate: $20 \mathrm{\mu V} \mathrm{s}^{-1}$ ) corresponds to a MCMB electrode measured in a Swagelok ${ }^{\circledR}$ cell and serves as a guide to the eye, while the current scale is arbitrary.

with an arbitrary current scale and only serves as a guide to the eye here.

The red line shows the change in resonance frequency $d f$, which in the beginning of the measurement does not change significantly up to a potential of $1.5 \mathrm{~V}$, which is the onset of cathodic currents. Reaching lower potentials, the frequency drops further, until it reaches a constant value at around $0.3 \mathrm{~V}$. In the reverse scan the frequency remains constant until the anodic peaks in the range of $1.0 \mathrm{~V}$ to $1.5 \mathrm{~V}$ are reached. A magnification of this area is shown in Figure 8 (b). As soon as the first large anodic peak appears in the CV, the resonance frequency raises by about $2.5 \mathrm{kHz}$. Passing the next peaks, the EQCM signal shows a frequency increase at each peak, which more or less is proportional to the peak charge $(d f \propto d Q)$.

Similar observations can be made when analysing the damping $d w$. The damping also remains constant in the beginning of the potential cycle. Below $1.5 \mathrm{~V}$ it shows an initial drop, before it strongly increases at low potentials. Having reached the lower vertex potential, the damping remains constant, just as the frequency before. Just as the first anodic peak is reached, the damping drops by $10.5 \mathrm{kHz}$ and with every following peak a proportional $d w$-drop to the peak charge is observed. At the end of the potential cycle, $d f$ as well as $d w$ do not reach the original frequency of the fresh electrode.

\section{Discussion}

In literature it has been described that $\mathrm{Na}^{+}\left(G_{x}\right)_{y}$-complexes may intercalate into graphite at low electrode potentials $24,25,26,27,28$, ${ }^{34}$ but the mechanism is not clear. XRD and STM are techniques, especially when used under operating conditions, which can deliver valuable information about the crystal phases and their changes caused by a sodiation of the graphite lattice. XRD being an integral technique allows to accurately determine lattice expansions and the staging behaviour of the ternary Na-GIC, while STM as a local technique helps to unravel crystal phase transitions and possibly their kinetics, analyse the lattice expansion of single graphene planes within the graphite lattice and to directly measure diffusion processes in the graphite lattice.

Both techniques allow to measure the graphite lattice expansions upon sodiation. The observed lattice expansions to more than $11 \AA$ found by XRD and STM when sodiating the graphite electrodes are much larger than the ionic radius of $\mathrm{Na}^{+}$ (1.02 Å). Thus, it does not seem plausible that "naked" Na-ions intercalate, but obviously together with their solvation shells (7.27 ̊̊ lateral expansion of a $\mathrm{Na}^{+}\left(\mathrm{G}_{2}\right)_{1}$-complex). ${ }^{26}$ This results in the formation of ternary Na-GICs, which according to the XRD data intercalate into every second graphite layer forming ternary stage $2 \mathrm{Na}$-GICs (cf.

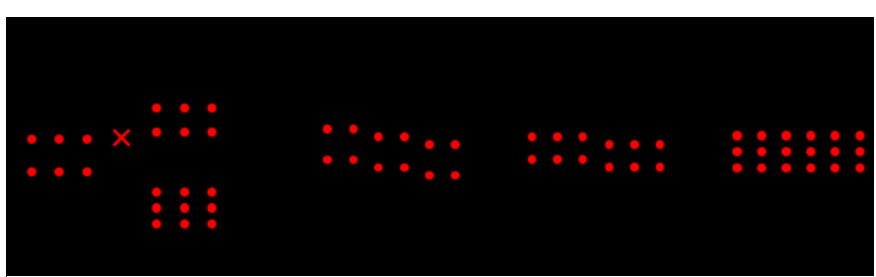

Figure 9: Different staging models in comparison: (a) Classical staging and (b) DaumasHerold ${ }^{38}$ staging. 
Table 1) and as was suggested earlier. ${ }^{24,} 25,26,27,28,34$ According to Kim et al. ${ }^{26}$, the $11 \AA$ interlayer spacing may be caused by doubly stacked $\mathrm{Na}^{+}\left(\mathrm{G}_{\mathrm{x}}\right)_{\mathrm{y}}$-complexes inside the graphite planes. In addition, a phase transition from a stage $3 \mathrm{Na}-\mathrm{GIC}$ via a stage $2 \mathrm{Na}-\mathrm{GIC}$ to a stage $1 \mathrm{Na}-\mathrm{GIC}$ is observed upon full discharge. In a classical model of staging, the ion insertion would strictly only occur in every third layer across the entire crystal for a stage 3 $\mathrm{Na}-\mathrm{GIC}$, and in every second layer for a stage $2 \mathrm{Na}-\mathrm{GIC}$. With such a model (Figure 9 (a)) the phase transition from a stage 3 to the stage $2 \mathrm{Na}-\mathrm{GIC}$ can hardly be explained, since this would require a diffusion of the already inserted $\mathrm{Na}^{+}\left(G_{x}\right)_{y}$-complexes perpendicular to the graphene sheets, where the diameter of a carbon-honeycomb amounts to $2.84 \AA{ }^{37}$ Consequently, it is believed that the $\mathrm{Na}^{+}\left(G_{x}\right)_{y}$-complexes do not follow the standard staging mechanism as presented in Figure 9 (a), but follow another staging mechanism. The Daumas-Herold ${ }^{38}$ staging mechanism (Figure 9 (b)) can explain a transition from stage 3 to stage 2 by a continuous lattice filling with $\mathrm{Na}^{+}\left(G_{x}\right)_{y^{-}}$ complexes. Such a mechanism appears more plausible than the classical staging model, as especially in the beginning of the intercalation reactions all graphene interlayers should be equally prone to ion intercalation. Therefore it is believed that intercalation starts at random sites. However, due to the mechanical swelling and electrostatic interactions, a statistical filling of the lattice does not seem to be energetically favourable. During the first three reduction peaks, the changes measured in the XRD appear to be continuous, the lattice constants and the staging number continuously decrease ( $c f$. Figure SI6 and SI7). However, the time resolution of the XRD measurements is limited, therefore it cannot be excluded that intermediate higher "stable" staging numbers are associated with each one of those peaks. Just above the large reduction peak in Figure 2 (b), (d), and (h), the presence of the stage 2 compound determines the XRD. This means, that a certain degree of ordering must have happened during ion insertion. It is possible that individual domains inside the graphite crystals with stage 2 have formed. The total composition of the Na-GIC at this potential has been only determined approximately due to the scattering in the charge/discharge curves. However, based on the compositions in $\mathrm{G}_{2}$ and $\mathrm{G}_{4}$, the maximum degree of intercalation at this point can be approximated with the formula $\mathrm{NaC}_{48}$. This means that in the actual intercalation layer, one $\mathrm{Na}$ ion is present for every $24^{\text {th }} \mathrm{C}$ atom. Obviously, further insertion of the solvated ions into a single layer is not possible. This is understandable giving the size of solvated ions and of the graphite honeycomb units. Further insertion must take place at other positions. Therefore a major phase transition is connected with continued intercalation, leading to the large reduction peak in the $\mathrm{dQ} / \mathrm{dV}$-plots and the voltammograms. Across the domain boundaries, ions can be transferred so that in the end a stage $1 \mathrm{Na}-\mathrm{GIC}$ results. Therefore, peaks representative of both stage 1 and stage 2 are present in parallel until the phase transformation is complete.

Taking a closer look on the graphite lattice expansion as a function of the glyme molecule, illustrated in Figure SI 8, one sees that for the fully sodiated discharge state, the interlayer spacing linearly increases with an increase in glyme length with the exception of the $\mathrm{G}_{3}$-complex, which might have a smaller volume than the other $\mathrm{Na}^{+}\left(\mathrm{G}_{x}\right)_{y}$-complexes, since only one $\mathrm{G}_{3-}$ molecule coordinates the Na-ions instead of three for $\mathrm{G}_{1}$, two for $\mathrm{G}_{2}$ and one large molecule in case for $\mathrm{G}_{4}$.

The propagation of the extended graphite layers, which is observed in the STM images, result from the inserted $\mathrm{Na}^{+}\left(G_{x}\right)_{y^{-}}$ complexes, diffusing inside the graphite lattice. Thus, by following the movement of the graphite extension, one has a direct measure of diffusion rates of the intercalated $\mathrm{Na}^{+}\left(\mathrm{G}_{x}\right)_{y^{-}}$ species inside the graphite lattice. Analysing the diffusion rates, one sees that the $\mathrm{G}_{3}$-complexes $\left(5.9 \mathrm{~nm} \mathrm{~s}^{-1}\right.$ ) diffuse significantly slower than the $\mathrm{G}_{4}$-complexes $\left(22.1 \mathrm{~nm} \mathrm{~s}^{-1}\right)$. This may directly contribute to the observed time difference of fully sodiating an HOPG chip in the $\mathrm{G}_{3}$-electrolyte (more than 20 minutes, Figure SI 9) compared to the experiment of Kim et al. ${ }^{26}$ in $G_{2}$ (3 minutes).

One possible explanation for these differences can be found in the composition of the $\mathrm{Na}^{+}\left(G_{x}\right)_{y}$-complexes (Figure 1). In literature it is suggested that the most favourable oxygencoordination number $(\mathrm{CN})$ of an alkali ion in glyme-solutions is in the range of 4 to $7,39,40,41,42,43$ resulting in the formation of a $\mathrm{Na}^{+}\left(\mathrm{G}_{1}\right)_{3^{-}}$, a $\mathrm{Na}^{+}\left(\mathrm{G}_{2}\right)_{2^{-}}$and a $\mathrm{Na}^{+}\left(\mathrm{G}_{4}\right)_{1}$-complex. The $\mathrm{Na}^{+}\left(\mathrm{G}_{3}\right)_{1^{-}}$ complex with a $\mathrm{CN}$ of 4 is slightly under-coordinated, while the $\mathrm{Na}^{+}\left(\mathrm{G}_{3}\right)_{2}$-complex is slightly over-coordinated. Both $\mathrm{Na}^{+}\left(\mathrm{G}_{3}\right)^{-}$ complexes are sketched in Figure SI 14, while the excess of the glyme molecule in the $\mathrm{Na}^{+}\left(\mathrm{G}_{3}\right)_{2}$-complex results in the formation of a dangling tail. This steric hindrance of the $\mathrm{Na}^{+}\left(\mathrm{G}_{3}\right)_{2}$-complex has been believed to be the reason for the sluggish diffusion in the graphite electrode. ${ }^{34}$ Simple evaporation experiments (Figure SI 14), however, where a specific amount of electrolyte was exposed to a vacuum in order to remove all the unbound glyme molecules from the electrolyte, rather suggest the $\mathrm{Na}^{+}\left(\mathrm{G}_{3}\right)_{1}$-complex as the more probable compound, as is sketched in Figure 1. Also the weight change observed during the full sodiation of an HOPG chip (Figure SI 9) clearly suggests the intercalation of the $\mathrm{Na}^{+}\left(\mathrm{G}_{3}\right)_{1}$-complex. Thus, another possibility instead of the steric hindrance of the $\mathrm{Na}^{+} \mathrm{G}_{3}$-complex resulting in the sluggish diffusion and the different electrochemistry is the under-coordination of the $\mathrm{Na}^{+}$in the $\mathrm{Na}^{+}\left(\mathrm{G}_{3}\right)_{1}$-complex, leading to the assumption that the balance between ionic bonding and covalent bonding between $\mathrm{Na}^{+}$and the graphite lattice must be correct. ${ }^{44}$ Thus, the assumptions from literature about the hampered diffusion due to the steric hindrance of the $\mathrm{Na}^{+}\left(\mathrm{G}_{3}\right)_{x}$-complexes do not seem plausible, but rather that the incomplete shielding of the solvation shell increases the $\mathrm{Na}^{+}$-graphite interaction inhibiting diffusion.

Analysing the frequency $f$ plus the damping $w$ of an EQCM-signal allows to apply the EQCM-technique as an in-situ hydrodynamic spectroscopy ${ }^{45}$ tool to analyse structural changes of porous electrodes in a similar manner as other techniques like XRD, for example when electrode particles change their size upon sodiation/de-sodiation. This technique is much more powerful than the standard Sauerbrey-valid EQCM, which only holds true for acoustically thin, homogeneous, and rigid films. ${ }^{46,47,48}$ In the present case, however, porous, thick particles are coated on a quartz, resulting in a frequency shift, an intensity loss and a broadening of the resonance curve (Figure SI 15). Immersed 
into an electrolyte, the system is far from the ideal Sauerbreycase. If one for example calculates the expected frequency change with a purely gravimetric model, i.e. Sauerbrey, of the first de-sodiation peak in Figure 8 (b) from the electric charge inserted into the graphite, one would obtain a frequency change of $500 \mathrm{~Hz}$. The measured frequency drop occurring at this peak, however, is five times larger.

Thus, other models must be applied, like the model suggested by Daikhin et al., ${ }^{45,47}$ not only taking viscoelastic effects into account, but also morphological parameters of the particles coated on the quartz, like porosity, roughness and particle size. This model, however, requires hemi-spherical, homogenously distributed particles with a sharp size distribution. Here, these requirements are not matched well enough, which is why Daikhin's model can only be applied qualitatively. Taking a close look to Daikhin's equations, which are summarized in the Supplemental Information in equations (SI 1 ) to (SI 7), one finds that under otherwise identical conditions, the shift of the resonance frequency to lower values (corresponding to a more negative $d f$ ) caused by a rough film containing particles of radius $r$ becomes the larger, the larger the particle size $r$ is, and the damping $w$ increases as well, $d w$ being positive.

Hence, the frequency decrease observed during the cathodic potential sweep (Figure 8 (a)) can be explained by the particle growth, when the $\mathrm{Na}^{+}\left(\mathrm{G}_{3}\right)$-complexes intercalate into the graphite. At the same time, the increase of the particle size results in an increase of $d w$, as expected. In Figure 8 (a) $d f$ remains constant below $0.3 \mathrm{~V}$. Here, the electrode is probably fully sodiated, which is why the particles no longer grow and $d f$ as well as $d w$ remain constant until the de-sodiation peaks are reached, where the previous behaviour is reversed.

Highly interesting is the behaviour during de-intercalation shown in Figure 8 (b): For the main de-intercalation peak connected, as known from XRD, to a phase transition from stage 1 to stage 2 , the particles are expected to shrink considerably. In fact, the EQCM shows a corresponding large step in $d f$ (towards less negative values) and in $d w$ (less positive), fully consistent with the expectations from the model. Other than from XRD, however, the EQCM data also resolve corresponding steps in $d f$ for the subsequent smaller peaks, roughly scaling with the amount of charge involved. In a purely gravimetric (Sauerbrey) regime, this would be expected, as $d f$ would be immediately connected with the mass change of the electrode layer. However, the purely gravimetric model does not apply here, and the damping shows similar steps. Even though a quantitative analysis cannot be done at the present stage, this might be explained by a corresponding stepwise change in the particle size. Therefore it would be plausible to connect these additional electrochemical peaks to phase transformations between stage 1 and higher stage compounds. Further experimental studies and model refinements will be required to clarify that issue. It is nevertheless remarkable how well in this system EQCM responds to the structural changes in the graphite particle layer.

For a fully reversible system like a rechargeable battery, one would expect that the particles reach their original state after a full cycle, which obviously is not the case. The experiment shown here is the first potential cycle, where typically an irreversible SEl-formation takes place, ${ }^{49}$ resulting in the irreversible frequency- and damping-shift. In the second cycle, the SEI-formation is strongly decreased (Figure SI 17) resulting in a lowered irreversible change in $d f$ and $d w$. The irreversible changes still observed can have different reasons, for instance the enhanced SEl-formation due to the reactive Au-surface and the large volume expansions of the graphite particles leading to cracks in the previously formed SEI-layer. A similar SEI formation is also observed in the $\mathrm{G}_{4}$-electrolyte (Figure $\mathrm{SI} 16$ (c)) and in the STM-series shown in Figure SI 10 and 12. According to electrochemical data, the 3D representations of the STM data and the EQCM data, the SEI-formation sets in at potentials below $1.0 \mathrm{~V}$, however there is still a lack in understanding the formation mechanism, the chemical composition and the morphology of the SEI, which in future could be studied in further detail by EQCM, ${ }^{50}$ EC-STM ${ }^{49}$ or other microscopic and spectroscopic techniques, such as the very recently published synchrotron XPS-study by Maibach et al. ${ }^{33}$ In their experiment, the SEl-formation on graphite in a $\mathrm{Na}-\mathrm{FSI} / \mathrm{G}_{4}$-electrolyte was investigated, resulting in a $3 \mathrm{~nm}$ to $8 \mathrm{~nm}$ thick SEl-film mainly composed of salt decomposition products and hydrocarbons. This film formation results in the irreversible $d f$ - and $d w$ changes of EQCM and showing up as the surface film in STMdata presented in this study. In STM, the STM-tip can usually penetrate the organic compounds of the SEI-layer, as was shown earlier, ${ }^{49}$ whereas the precipitated inorganic salt decomposition products result in the surface roughness observed in the 3D-STM data presented in Figure SI 10 and $12 .{ }^{49}$ This inorganic precipitate is also the reason for the fuzzy STMimages. STM images may also become fuzzy because of a high subsurface mobility of the $\mathrm{Na}^{+}\left(\mathrm{G}_{\mathrm{x}}\right)_{y}$-complex during phase transitions.

It is worth mentioning that the battery community is already seeking for a possibility to apply EQCM to battery research by coating the quartzes with electrode particles. There are a few examples in literature, where the $\mathrm{Li}^{+}$-intercalation into vanadium oxide, ${ }^{51,52}$ the SEI formation in $\mathrm{LIBs}^{50}$ or the charging behaviour of carbon cathodes in LiS-batteries is studied. ${ }^{53} \mathrm{In}$ these studies, frequency changes upon charging/discharging are only in the range of a few $\mathrm{Hz}$. The study by Novák et al. ${ }^{50}$ showed reasonable frequency changes, which are of the same order of magnitude as observed here. In addition, there are very well developed theoretical models to treat EQCM well beyond gravimetry. ${ }^{45}, 48$ The excellent correlation between the electrochemical phase transitions and the EQCM signal correlated with sodiation/de-sodiation of graphite in the $\mathrm{G}_{3}-$ electrolyte may represent an excellent candidate for testing the theoretical models and to close the gap between theory and experiment. For this it would be crucial to make use of particles, which are homogenous in size, equally distributed on the quartz, and at least approximately hemi-spherical.

Another open question arising from the present study is, how the $\mathrm{Na}$-ions are coordinated by the glyme molecules, both, in solution and inside the graphite host. Theoretical studies could help in order to predict the ideal solvation shell of the $\mathrm{Na}$-ions, by which the optimal balance of ionic and covalent bonding 
between the Na-ions and the graphite lattice can be reached. This might also help to explain why the staging behaviour in triglyme is so different from the other glymes. Moreover, taking into consideration the large volume expansion by almost a factor of 4, it is astonishing that these systems can be cycled for several thousand times without a significant loss in capacity. ${ }^{25}$, 26, 27 Understanding this remarkable behaviour may also be important for other battery systems, since it may allow for an improved performance and lifetime of batteries in general.

\section{Conclusions}

In this study the reversible $\mathrm{Na}^{+}$intercalation into graphite is investigated by a variety of powerful techniques, including inoperando XRD, EC-STM and EQCM. The combined use of these techniques allows to gain information about the cointercalation mechanism of the solvated $\mathrm{Na}^{+}$: The $\mathrm{Na}$-ions cointercalate into the graphite together with their solvation shell as $\mathrm{Na}^{+}\left(G_{x}\right)_{y}$-complex to form first an intermediate stage 2 ternary $\mathrm{Na}-\mathrm{GICs}$, followed by a phase transition to stage 1 , yielding theoretical capacities of $112 \mathrm{mAh} \mathrm{g}^{-1}$ upon full discharge ( $\mathrm{NaC}_{18}$ in $\mathrm{G}_{1}, \mathrm{G}_{2}$ and $\mathrm{G}_{4}$, respectively). The exceptional $\mathrm{G}_{3}$-system, where the co-intercalation of the under-coordinated $\mathrm{Na}^{+}\left(\mathrm{G}_{3}\right)_{1}$-complexes results in a different electrochemistry and a hampered diffusion, forms nevertheless also an intermediate stage $2 \mathrm{Na}-\mathrm{GIC}$, transforming into a fully sodiated stage $1 \mathrm{Na}$ GICs with a different stoichiometry of $\mathrm{NaC}_{30}\left(70 \mathrm{mAh} \mathrm{g}^{-1}\right)$. The information about the phase transitions in the graphite lattice upon sodiation/de-sodiation were obtained by XRD as an integral technique, and then complemented by STM studies at the nanoscale, where monoatomic step edges and phase transitions on the nanoscale were analysed. While XRD allows to precisely quantify phase transitions, STM permits to go a step beyond and analyse them locally by creating 3D topographic images. The data on the lattice expansion determined by STM and XRD were in good agreement. Additionally, STM proved to be an important tool to study kinetic parameters, such as the diffusion rates of the $\mathrm{Na}^{+}\left(G_{x}\right)_{y}$-complexes inside the graphite host, a unique application of STM so far.

There are hints of a SEl-formation on the graphite electrode due to the electrochemical reduction of the glyme molecules; they were visible in the STM-images as well as in the EQCM-data. Here, further studies must be carried out in order to reach a deeper understanding of the formation mechanism, the chemical composition as well as topographic properties.

So far, there is a desire from the battery community to apply EQCM to battery systems, however, there is also a lack in electrochemical systems, by which the far developed theoretical models can be proofed. Due to its unique properties and very pronounced correlation between electrochemistry and EQCM-signal, the herein presented EQCM-data on the deintercalation of $\mathrm{Na}^{+}\left(\mathrm{G}_{3}\right)_{1}$-complexes from graphite seem to be a suitable candidate to close the gap between theory and experiment by using it as a "calibration"-system. During deintercalation a clear correlation between the EQCM parameters resonance frequency/damping and the electric current (charge) was found that was beyond the gravimetric region. The observed changes could be qualitatively correlated with the changes in the graphite particle sizes upon sodiation/desodiation.

The systems studied are of high relevance for future developments in the field of $\mathrm{Na}$-ion batteries. It is found that an optimum balance between ionic and covalent bonding of the $\mathrm{Na}^{+}\left(\mathrm{G}_{x}\right)_{y}$-complexes enables the $\mathrm{Na}^{+}$-intercalation into graphite, which can be influenced by the structure of the solvation shell around the Na-ions. The crucial parameter to look at is the oxygen-coordination number. A coordination number too small results in sluggish kinetics or even completely inhibits an intercalation. On the other hand, steric hindrance can occur for over-coordinated Na-ions, also having a negative effect on the intercalation. Thus, by tailoring the solvation shell such that the $\mathrm{Na}$-ion is fully coordinated and the volume of the thus formed complex is as small as possible, further improvements on the battery performance are expected. This can be an important step to the commercialization of the Na-ion battery technology.

\section{Acknowledgements}

This work was funded by the German Ministry of Education and Research (BMBF) within the Sino-German Network on Electromobility under project no. 16N11930, which is gratefully acknowledged. The support of Prof. U. Heiz (Chemistry Department, Technische Universität München), Prof. H. A. Gasteiger (Chemistry Department, Technische Universität München), and Prof. A. C. Knoll (Institute of Informatics VI, Technische Universität München) and the use of their facilities are appreciated. The authors thank Prof. H. Fritze (Technische Universität Clausthal) for providing his software to automatically fit the admittance data from the EQCM measurements, and Mr. L. Asen (Technische Universität München) for designing the EQCM cell. Prof. D. Johannsmann (Technische Universität Clausthal) is thanked for helpful discussions. The support by Newcastle University is gratefully acknowledged.

\section{Notes and references}

1

M. H. Han, E. Gonzalo, G. Singh and T. Rojo, Energy Environ. Sci., 2015, 8, 81-102.

2 N. Yabuuchi, K. Kubota, M. Dahbi and S. Komaba, Chem. Rev., 2014, 114, 11636-11682.

3 V. Palomares, P. Serras, I. Villaluenga, K. B. Hueso, J. Carretero-González and T. Rojo, Energy Environ. Sci., 2012, 5, 5884.

4 M. D. Slater, D. Kim, E. Lee and C. S. Johnson, Adv. Funct. Mater., 2013, 23, 947-958.

$5 \quad$ M. Valvo, F. Lindgren, U. Lafont, F. Björefors and K. Edström, J. Power Sources, 2014, 245, 967-978.

6 M. Dahbi, N. Yabuuchi, K. Kubota, K. Tokiwa and S. Komaba, Phys. Chem. Chem. Phys. PCCP, 2014, 16, 1500715028.

7 D. Kundu, E. Talaie, V. Duffort and L. F. Nazar, Angew Chem Int Ed Engl, 2015, 54, 3431-3448. 
R. D. Shannon, Acta Crystallogr. Sect. A, 1976, 32, 751-767. 35 D. W. Su, S. X. Dou and G. X. Wang, J. Mater. Chem. A, 2014, 2, 11185-11194.

X. Xu, M. Yan, X. Tian, C. Yang, M. Shi, Q. Wei, L. Xu and L. Mai, Nano Lett., 2015, 15, 3879-3884.

W. Wan and H. Wang, Int. J. Electrochem. Sci., 2015, 10, 3177-3184.

H. Pan, Y.-S. Hu and L. Chen, Energy Environ. Sci., 2013, 6, 2338.

S. P. Ong, V. L. Chevrier, G. Hautier, A. Jain, C. Moore, S. Kim, X. Ma and G. Ceder, Energy Environ. Sci., 2011, 4, 3680.

X. Xiang, K. Zhang and J. Chen, Adv. Mater., 2015, 27, 5343-5364.

F. Klein, B. Jache, A. Bhide and P. Adelhelm, Phys. Chem. Chem. Phys., 2013, 15, 15876.

Y. Cao, L. Xiao, M. L. Sushko, W. Wang, B. Schwenzer, J. Xiao, Z. Nie, L. V Saraf, Z. Yang and J. Liu, Nano Lett., 2012, 12, 3783-7.

K. Kubota, N. Yabuuchi, H. Yoshida, M. Dahbi and S. Komaba, MRS Bull., 2014, 39, 416-422.

R. Yazami and P. Touzain, J. Power Sources, 1983, 9, 365371.

M. M. Doeff, Y. Ma, S. J. Visco and L. C. De Jonghe, J.

Electrochem. Soc., 1993, 140, 169-170.

P. Thomas, J. Ghanbaja and D. Billaud, Electrochim. Acta, 1999, 45, 423-430.

P. Thomas and D. Billaud, Electrochim. Acta, 2002, 47 3303-3307.

K. Nobuhara, H. Nakayama, M. Nose, S. Nakanishi and H. Iba, J. Power Sources, 2013, 243, 585-587.

Y. Okamoto, J. Phys. Chem. C, 2013, 118, 16-19.

B. Jache and P. Adelhelm, Angew. Chem. Int. Ed. Engl., 2014, 53, 10169-73.

Z. Zhu, F. Cheng, Z. Hu, Z. Niu and J. Chen, J. Power Sources, 2015, 293, 626-634.

H. Kim, J. Hong, G. Yoon, H. Kim, K.-Y. Park, M.-S. Park, W.S. Yoon and K. Kang, Energy Environ. Sci., 2015, 8, 29632969.

B. A. Jache, J. O. Binder, T. Abe and P. Adelhelm, Phys. Chem. Chem. Phys., 2016, 18, 14299-14316.

I. Hasa, X. Dou, D. Buchholz, Y. Shao-Horn, J. Hassoun, S. Passerini and B. Scrosati, J. Power Sources, 2016, 310, 2631.

G. C. Ri, C. J. Yu, J. S. Kim, S. N. Hong, U. G. Jong and M. H. Ri, J. Power Sources, 2016, 324, 758-765.

H. Kim, G. Yoon, kyungmi Lim and K. Kang, Chem. Commun., 2016, 52, 12618-12621.

Z. Guan, X. Shen, R. Yu, Z. Wang and L. Chen, Electrochim. Acta, 2016, 222, 1365-1370.

K. Gotoh, H. Maruyama, T. Miyatou, M. Mizuno, K. Urita and H. Ishida, J. Phys. Chem. C, 2016, acs.jpcc.6b10962. J. Maibach, F. Jeschull, D. Brandell, K. Edstrom and M. Valvo, ACS Appl. Mater. Interfaces, 2017, accepted manuscript.

B. A. Jache, J. O. Binder, T. Abe and P. Adelhelm, Phys. Chem. Chem. Phys., 2016, 18, 14299-14316.
H. Kim, J. Hong, Y.-U. Park, J. Kim, I. Hwang and K. Kang, Adv. Func. Mater., 2014, 534-541.

J. A. Seel and J. R. Dahn, J. Electrochem. Soc., 2000, 147, 892.

P. Trucano and R. Chen, Nature, 1975, 258, 136-137.

N. Daumas and A. Hérold, C. R. Seances. Acad. Sci., 1969, Ser. C 268, 373.

C. J. Pedersen and H. K. Frensdorff, Angew. Chemie Int. Ed. English, 1972, 11, 16-25.

C. J. Pedersen, Angew. Chemie, 1988, 100, 1053-1059.

T. Matsui and K. Takeyama, Electrochim. Acta, 1998, 43, 1355-1360.

C. P. Rhodes, M. Khan and R. Frech, J. Phys. Chem. B, 2002, 106, 10330-10337.

W. A. Henderson, 2006, 13177-13183.

H. Moriwake, A. Kuwabara, C. A. J. Fisher, M. Nose, H. Nakayama, S. Nakanishi, H. Iba and Y. Ikuhara, Meet. Abstr. - ECS PRIME 2016, 2016.

N. Shpigel, M. D. Levi, S. Sigalov, O. Girshevitz, D. Aurbach, L. Daikhin, P. Pikma, M. Marandi, A. Jänes, E. Lust, N. Jäckel and V. Presser, Nat. Mater., 2016, 15, 570-577.

D. A. Buttry and M. D. Ward, Chem. Rev., 1992, 92, 13551379.

L. Daikhin, E. Gileadi, G. Katz, V. Tsionsky, M. Urbakh and D. Zagidulin, Anal. Chem., 2002, 74, 554-561.

D. Johannsmann, The Quartz Crystal Microbalance in Soft Matter Research, 2015.

L. Seidl, S. Martens, J. Ma, U. Stimming and O. Schneider, Nanoscale, 2016, 8, 14004-14014.

P. Novák, F. Joho, M. Lanz, B. Rykart, J.-C. Panitz, D. Alliata, R. Kötz and O. Haas, J. Power Sources, 2001, 97-98, 39-46. H.-K. Park, K. Podolske, Z. Munshi, W. H. Smyrl and B. B. Owens, J. Electrochem. Soc., 1991, 138, 627-628. E. Shouji and D. A. Buttry, Electrochim. Acta, 2000, 45, 3757-3764.

H. L. Wu, L. A. Huff, J. L. Esbenshade and A. A. Gewirth, ACS Appl. Mater. Interfaces, 2015, 7, 20820-20828. 